\title{
Health technology assessment: time for a randomised controlled trial of the role of lung volume reduction surgery in the treatment of emphysema
}

\author{
D A Lomas, N Caine, F C Wells on behalf of the Lung Volume Reduction Surgery Trial Project Team
}

Emphysema is an important cause of morbidity and mortality, accounting for approximately 18 deaths per 100000 population aged 55-74 in England and Wales in 1994. ${ }^{1}$ Chronic bronchitis and emphysema are the commonest causes of abnormal spirometric values and, by middle age, $18 \%$ of male and $14 \%$ of female smokers have forced expiratory volume in one second $\left(\mathrm{FEV}_{1}\right)$ values more than two standard deviations below the mean predicted. ${ }^{2}$ Emphysema is characterised by abnormal and permanent enlargement of air spaces distal to the terminal bronchiole. It is accompanied by destructive changes of the alveolar walls with coalescence of alveoli into large bullous spaces of varying size and distribution. ${ }^{3}$ Classically, it has been regarded as a diffuse process in which surgery can offer little other than in the presence of one or more giant bullae, when surgical resection may result in improved expansion of the residual lung and a lessening of the symptoms of breathlessness.

In recent times lung transplantation has been added to the surgical armamentarium for the treatment of emphysema. This is reserved for patients at the end stage of their disease and, although significantly enhancing quality of life, it exposes the patient to the possibility of infection or rejection with life long dependency on immunosuppression therapy. Although life may be extended significantly for many patients, the four year survival rate stands at only $50-60 \% .^{4}$ Because of this, and the shortage of donors, there is great demand for some kind of intervention, short of transplantation, available to patients in earlier stages of the disease.

Lung volume reduction surgery was first reported in 1957 by Otto Brantigan. ${ }^{5}$ He suggested that, in the normal state, bronchi are held open by the elastic pull of the expanded lung. In emphysema this is lost and the airways tend to close because of the loss of circumferential pull. $\mathrm{He}$ also postulated that normal diaphragm and chest wall movement is impaired by being splinted in the inflated position by the massive increase in lung volume that characterises this condition. Brantigan suggested that, by reducing the intrathoracic volume by resecting the most affected $20 \%$ of lung, normal elastic pull of bronchi could be restored and more efficient function of chest wall and diaphragm would result by allowing the thorax to return to the normal exhalation volume at rest. Whilst many patients derived benefit from lung volume reduction surgery, the high postoperative morbidity and mortality ${ }^{6}$ precluded its widespread use amongst thoracic surgeons.

In 1995 Cooper and colleagues re-introduced lung volume reduction surgery because of the subjective improvement in patients with end stage emphysema following single lung transplantation over and above that which they had observed in patients transplanted for fibrotic lung disease. ${ }^{7}$ The postulate was that the reduction in intrathoracic volume had helped the function of the other lung. Cooper and colleagues focused not only upon the surgery but also the potential benefits of a rigorous rehabilitation programme developed for their lung transplant patients. They reported an improvement of $82 \%$ in $\mathrm{FEV}_{1}$ (0.77 1 to 1.41 ) in 20 patients, with no postoperative deaths. There were significant improvements in total lung capacity, residual volume, gas trapping, as well as exercise tolerance and quality of life profiles. ${ }^{8}$ Although the initial premise was that reduction in lung volume would allow more normal function of the diaphragm and chest wall, it rapidly became apparent that this was not the only effect. Patients with a homogeneous distribution of disease (such as observed with $\alpha_{1}$-antitrypsin deficiency) did not demonstrate the same improvement in lung function as did those with a distinct heterogeneous distribution.

Several other authors have reported similar findings, ${ }^{9-15}$ all of which are based on non-randomised, uncontrolled trials with widely differing operative and rehabilitation protocols. Despite these promising reports, Medicare has refused to fund further lung volume reduction surgery in the USA in the absence of a clinical trial. Moreover, the American Thoracic Society ${ }^{16}$ and others ${ }^{17-20}$ have emphasised the need for a controlled trial. Several points need to be considered: patient selection criteria, the role of preoperative exercise conditioning, use of a bilateral or unilateral surgical approach, apical or basal excision, long term survival, whether this type of surgery accelerates the decline in lung function after an initial period of improvement, the cost effectiveness of the treatment, and whether it should be offered to patients with $\alpha_{1}$-antitrypsin deficiency.

It is in this context that we have proposed, and are seeking funding for, a multicentre randomised controlled trial in the UK to compare lung volume reduction surgery and pulmonary rehabilitation with pulmonary rehabilitation alone. The aims are to evaluate the effectiveness of surgery in improving both symptoms and the lung function of patients with advanced emphysema who do not, as yet, require transplant surgery, and to estimate the costs of surgery compared with conventional medical therapy. Having succeeded in establishing agreement across six major UK thoracic surgery centres on the design of the trial, on the rehabilitation programme, and the surgical protocol, we are convinced that such a study is feasible, especially as only a modest number of patients is required. There will clearly be some variation between surgeons and cardiothoracic centres but the advantage of this approach is generalisability of results, allowing a successful protocol to be adopted by other centres following completion of the trial.

In conclusion, with so many people in the UK suffering from emphysema, the introduction of lung volume reduction surgery, especially in a non-standardised way using several different techniques, in differing patient populations with or without pulmonary rehabilitation has the potential to consume a vast amount of financial and physical resources. In the USA, due to the early widely reported "success" stories, the opportunity to recruit patients into a randomised controlled trial is diminished, ${ }^{21}$ although there are now plans to launch a large multicentre study. It 
is therefore internationally agreed that trials are needed and it is hoped that the UK group will make an important contribution to the proper evaluation of this new technology.

Papworth Hospital NHS Trust,

Papworth Everard,

Cambridge CB3 8RE, UK

DAVID A LOMAS

NOREEN CAINE

FRANCIS C WELLS

1 OPCS. Verbal enquiry. 1996.

2 Pride NB, Stockley RA. Chronic obstructive pulmonary disease. In: Weatherall DJ, Ledingham, JGG, Warrell DA, eds. Oxford textbook medicine. 3rd edn. Oxford: Oxford University Press, 1996: 2766-79.

3 American Thoracic Society. Standards for the diagnosis and care of patients with chronic obstructive pulmonary disease (COPD) and asthma. $\mathrm{Am}$ Rev Respir Dis 1986;136:225-44

4 Hosenpud JD, Novick RJ, Breen TJ, Keck B, Daily P. The Registry of the International Society for Heart and Lung Transplantation:

5 Brantigan OC, Mueller E. Surgical treatment of pulmonary emphysema. Am Surg 1957;23:789-804.

6 Brantigan OC, Mueller E, Kress MB. A surgical approach to pulmonary emphysema. Am Rev Respir Dis 1959;80:194-206.

7 Cooper JD, Lefrak SS. Is volume reduction surgery appropriate in the treatment of emphysema? Yes. Am $\mathcal{F}$ Respir Crit Care Med 1996;153:

8 Cooper JD, Trulock EP, Triantafillou AN, Patterson GA, Pohl MS, Deloney $\mathrm{PA}$, et al. Bilateral pneumectomy (volume reduction) for chronic obstructive pulmonary disease. $\mathcal{F}$ Thorac Cardiovasc Surg 1995;109:106-19.
9 Sciurba FC, Rogers R, Keenan RJ, Slivka WA, Gorcsan J, Ferson PF, et al.

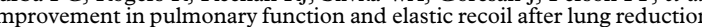
surgery for diffuse emphysema. $N$ Engl $₹$ Med 1996;334:1095-9.

10 Gaissert HA, Trulock EP, Cooper JD, Sundaresan RS, Patterson GA Comparison of early functional results after volume reduction for chronic obstructive pulmonary disease. F Thorac Cardiovasc Surg 1996;111:296307.

11 McKenna RJ, Brenner M, Gelb AF, Mullin M, Singh N, Peters H, et al. A randomised prospective trial of stapled lung reduction versus laser bullectomy for diffuse emphysema. F Thorac Cardiovasc Surg 1996;111 317-22.

12 Keenan RJ, Landreneau RJ, Sciurba FC, Ferson PF, Holbert JM, Brown $\mathrm{ML}$, et al. Unilateral thoracoscopic surgical approach for diffuse emphysema. F Thorac Cardiovasc Surg 1996;111:308-16.

13 Little AG, Swain JA, Nino JJ, Prabhu RD, Schlachter MD, Barcia TC Reduction pneumonoplasty for emphysema. Early results. Ann Surg 1995

14 Criner GJ, O’Brien G, Furukawa S, Cordova F, Swartz M, Fallahnejad M, et al. Lung volume reduction surgery in ventilator-dependent COPD

15 McKenna RJ, Fischel RJ, Brenner M, Gelb AF. Combined operations for lung volume reduction surgery and lung cancer. Chest 1996;110:885-8.

16 Fein AM, Branman SS, Casaburi R, Irvin CG, Make BJ, Rodarte JR, et al Lung volume reduction surgery. Am f Respir Crit Care Med 1996;154

17 Benditt JO, Albert RK. Lung reduction surgery. Great expectations and a cautionary note. Chest 1995;107:297-8.

18 Rusch VW. Lung reduction surgery: a true advance? 7 Thorac Cardiovas Surg 1996;111:293-5.

19 Make BJ, Fein AM. Is volume reduction surgery appropriate in the treatment of emphysema? No. Am ₹ Respir Crit Care Med 1996;153:1205-7.

20 Davies L, Calverley PMA. Lung volume reduction surgery in chronic obstructive pulmonary disease. Thorax 1996;51(Suppl 2):S29-34.

21 Snider GL. Health-care technology assessment of surgical procedures. The case of reduction pneumoplasty for emphysema. Am $\mathcal{F}$ Respir Crit Care 